\title{
Dialogue as the Conditio Humana: a Critical Account of Dmitri Nikulin's Theory of the Dialogical
}

\section{Bradley S. Warfield ${ }^{1}$}

(C) Springer Nature B.V. 2019

\begin{abstract}
Dmitri Nikulin is one of the few contemporary philosophers to have devoted books to the topic of dialogue and the dialogical self, especially in the last fifteen years. Yet his work on dialogue and the dialogical has received scant attention by philosophers, and this neglect has hurt the ongoing development of contemporary philosophical work on dialogicality. I want to address this lacuna in contemporary philosophical scholarship on dialogicality and suggest that, although Nikulin's account is no doubt insightful and thought-provoking, it is problematic for two main reasons: first, his account fails to recognize the proper relationship between dialogue and agency; and second, his enumeration of the necessary and sufficient conditions for dialogue contains conceptual inconsistencies.
\end{abstract}

Keywords Dmitri Nikulin · Dialogicality $\cdot$ The dialogical self · Dialogue $\cdot$ Agency

\section{Introduction}

Dmitri Nikulin is one of the few contemporary philosophers to have devoted books to the topic of dialogue and the dialogical self, especially in the last fifteen years (see also Lysaker and Lysaker 2008). ${ }^{1}$ His On Dialogue $(2006)^{2}$ is, to my knowledge, the first work devoted exclusively to dialogue by a professional philosopher in the twenty-first

\footnotetext{
${ }^{1}$ See also Lysaker and Lysaker 2008. Excellent work on the dialogical self has been done of course by psychologists, such as the founder of 'dialogical self theory,' Hubert Hermans, and others. See Hermans (2001, 2012a, b), Hermans et al. (1992); Hermans and Kempen (1993), Hermans and Hermans-Konopka (2010), Hermans and Gieser (2014), and Hermans and Dimaggio (2016) for the most relevant work.

${ }^{2}$ See Edward P. Butler's review of On Dialogue in the Graduate Faculty Philosophy Journal, Volume 28, Number 2, 2007, pp. 167-176.
}

Bradley S. Warfield

bradley.warfield@utrgv.edu

1 The University of Texas Rio Grande Valley, One West University Blvd., BMSLC 3.224,

Brownsville, TX 78520, USA 
century (see Butler 2007). And his later work, Dialectic and Dialogue (2010), ${ }^{3}$ draws from his earlier account of dialogue and elaborates on the relatively brief comparative analysis of dialogue and dialectic that he offered in On Dialogue (see Miller 2011). Yet his work on dialogue and the dialogical has received scant attention by philosophers (see Kögler 2010 and Fritz 2015), ${ }^{4}$ and this neglect has hurt the ongoing development of contemporary philosophical work on dialogicality. ${ }^{5}$ I want to address this lacuna in contemporary philosophical scholarship on dialogicality and suggest that, although Nikulin's account is no doubt insightful and thought-provoking, it is problematic for two reasons ${ }^{6}$ : first, his account fails to recognize the proper relationship between dialogue and agency; and second, his enumeration of the necessary and sufficient conditions for dialogue contains conceptual inconsistencies.

Early in On Dialogue, Nikulin rightly notes that the idea of dialogue is frequently invoked in 'contemporary philosophical and public debates' (2006, vii), but in such debates what dialogue is specifically is hardly ever worked out. It is too often used indiscriminately and rarely defined; its true nature being left vague and its parameters amorphous. Offering an explanation of this unfortunate conceptual ambiguity, Nikulin cites a familiar criticism of the modern Cartesian-inspired epistemology, with its sharp subject/object dichotomy: 'The reason for dialogue's being misunderstood in and by contemporary philosophy is, perhaps, due to the monologicality of modernity that results from its monosubjectivity, i.e., from a single, sole consciousness as the ultimate source of meaning and reference' (Ibid). He reiterates the basic problem with the Cartesian paradigm in Dialectic and Dialogue:

In a sense, monologue is a genuine expression of the Cartesian single-voiced and solitary consciousness that does not need the other or the voice of another, except perhaps for the infinite and unique voice, which the finite monoconsciousness either establishes within itself from the certainty of its own consciousness or, disappointed and incapable of overcoming its own solitude, altogether rejects. Monologue does not address anyone; it does not expect an answer and thus does not presuppose the other to respond and ask questions, because the monological consciousness itself decides when and which question to ask and what the appropriate answer will be $(2010,82)$.

\footnotetext{
${ }^{3}$ Mitchell Miller offers a thorough review of Dialectic and Dialogue in the Graduate Faculty Philosophy Journal, Volume 32, Number 1, 2011, pp. 177-189.

${ }^{4}$ Some philosophers have acknowledged Nikulin's work on dialogue, such as Kögler (2010) and Fritz (2015). For some scholarship outside of philosophy that has recognized Nikulin's work on dialogue, see Trimble (2009), Rule (2015), and Russell (2012).

5 Throughout this paper, I shall use the terms 'dialogicality' and 'the dialogical' interchangeably.

${ }^{6}$ An additional problem with Nikulin's account - namely, as Mitchell Miller puts it, regarding the 'relation of dialogue's anthropological status and its ontological status' $(2011,186)$ - emerges in Dialectic and Dialogue when he claims, 'Whoever chooses to stop dialogical conversation with others by an act of voluntary selfsuspension chooses not to be, because to be is to be in dialogue' (2010, 155; Italics mine), but I have chosen not to discuss the problem in this paper, as Miller has already offered an albeit brief treatment of it in his review.
} 
Indeed, Nikulin takes a rather strong position on the phenomenon of monologue, which remains consistent over the course of On Dialogue and Dialectic and Dialogue, namely, that monologue is impossible. ${ }^{7}$ This is because any utterance, Nikulin claims, is an address insofar as it seeks a reply. And insofar as it seeks a reply, it is a dialogue, at least potentially.

Regarding the Cartesian paradigm (but not necessarily the status of monologue), Nikulin agrees with thinkers such as Bakhtin (1982a, b, 1984a, b, 1986), Heidegger (2008), Gadamer (2004), Taylor (1985a, b, 1992a, b), Hubert Hermans et al., and the many excellent feminist critics like Held (1990), Cole (2008), and others. Indeed, as Nikulin himself notes in On Dialogue, his account of dialogue is strongly influenced by Bakhtin insofar as it is largely a response to the latter's account. Referring to the central difference between his account and Bakhtin's, Nikulin states that 'although Bakhtin conceives of dialogue as that which unveils the human as something unique in its being with others, his consideration is primarily a theory of the literary dialogue, one which comes out of the interpretation of literature' (2006, viii; Italics original).

The account of dialogue that Nikulin offers, by contrast, can be understood as a philosophical anthropology and ontology (ix). Notwithstanding this difference, and Bakhtin's literary leanings, Nikulin rightly claims that Bakhtin nevertheless recognizes the foundational role that dialogue, as a manifestation of dialogism, plays in human beings' lived experience and articulations of personhood: 'For Bakhtin, dialogicality, the very capacity for dialogue, turns out to be the most profound expression of a person's individuality, and at the same time of her communality in her communication with others, which is indispensable for being human (or being-human)' (34). Nikulin argues, rightly, that dialogue should not be understood 'solely as a linguistic phenomenon' (viii), and not just as a form of communication. 'Rather, dialogue is considered to be that which is important primarily for an understanding of the human being qua person, of the human in relation to being, and of being as it is present in the human' (Ibid). Dialogue, then, for Nikulin, is not just an aspect of the human condition-it is the human condition (Ibid).

\footnotetext{
${ }_{7}^{7}$ As Nikulin puts it, 'In a strict sense, monologue is simply impossible. As a speech of one single subject, monologue needs to be uttered. As uttered, monologue is always addressed. As addressed, monologue is addressed to the other, even if this other is the other of and within oneself. As addressed to the other, monologue presupposes a reply, because without a reply, monologue is neither meaningful nor can it be uttered. But a reply makes the monologue a dialogue, at least potentially. Thus, it is as though the monologue asks for permission to be excused from the presupposed other, who in turn renders the monologue into a dialogue that has forgotten itself' (2006, 193; Italics original).
} 


\section{Voice, Polyphony, and the Eidema}

Nikulin devotes the first part of On Dialogue to an examination of initial accounts of dialogue in the West, tracing its origins back before Socrates. ${ }^{8}$ But because my aim is to elucidate and evaluate Nikulin's own account, I will leave aside any discussion of the historical examination he offers. Instead, I want to look at the major concepts in Nikulin's account of dialogue and dialogicality, the first of which is voice.

Drawing on Bakhtin's claim that every human being capable of dialogue is a 'pure voice,' Nikulin argues that '[e]very voice that speaks is meant to be heard, and every voice that is heard is meant to be responded to, and thus every voice craves dialogue' (39). Echoing Bakhtin, Nikulin claims that 'A single, separate and isolated voice is impossible, because the voice needs to be directed toward, and heard by, the other' (40). Nikulin is identifying an implicit demand for reciprocity that all human agents have in dialogical encounters. This means that the presence of any voice implies a plurality of other voices, or what Nikulin calls a 'community of voices' (Ibid).

That Nikulin writes of 'every voice that speaks' and 'every voice that is heard' might suggest that he means by 'voice' only those verbal utterances perceptible by auditory function. But instead, Nikulin takes 'voice' to designate not only verbal utterances but also nonverbal ones, as well as all manner of gestures. So, it is important to keep in mind that 'speech' and 'voice' should be understood broadly. Thus, the deaf nonverbal person, for example, has the same demand to speak and be heard as anyone else because they can communicate through gestures (39).

In speaking of a plurality of other voices, Nikulin is borrowing Bakhtin's notion of 'polyphony.' Nikulin writes, 'The appropriate musical metaphor that adequately represents the structure of interaction among a plurality of independent, yet not isolated, personal voices, voices which are capable of being uttered in each other's presence, is that of polyphony' (46). The reason why personal voices are independent, yet not isolated, is that a voice cannot exist and be uttered meaningfully without the presence of an other. 'A monological discourse is thus utterly impossible; even in the absence of

\footnotetext{
${ }^{8}$ Some passages that are especially illuminating for how Nikulin understands these origins are the following: '[T]he whole literary genre (eidoys syggraphēs), which is a genre of dialogue as speech or discussion involving questions and answers. Initially, dialogue was taken simply as a conversation between two or more persons (Latin sermo), each reaching for and needing the other' (2006, 1; Italics original); 'A new meaning of dialogue, namely dialogue as a way of life — of philosophical life - where the theoretical is intertwined with the practical in the activity of conversation, is brought about by Socrates, who is a walking and living embodiment of dialogue' (3); 'Socrates discovers dialogue as an elenchic genre, which is apt for the consideration of a subject matter from various perspectives, as well as for proofs and refutations' (Ibid; Italics original), where 'the Socratic elenchus' is 'the refutation of a proposed claim by demonstrating the viability of its opposite' (14); 'For Plato, dialogue primarily appears as a logos of a particular kind-a written imitation of oral conversation - without which, and outside of which, humans cannot exist qua persons and cannot express any aspect of themselves...which Plato characterizes in the Sophist as being the soul's silent conversation, dialogos, with herself in herself' (Plato. Soph. 263 e, entos tes psykhes pros hayten dialogos aney phones. Cp. Theaet. 189 e; 15, Italics original); 'However, the manifesto of modern philosophy, Descartes' Meditations, which presents the new finite subjectivity as that which perceives itself in solitude, which attends primarily to itself and not to the other, as alone and existing only vis-à-vis the infinite and divine subjectivity, is consciously written as an anti-dialogue' (16; Italics original); and 'Because of this, even occasionally using dialogue to present their views, modern philosophers rarely reflect on the meaning and notion of dialogue as such within a systematic context' (17; Italics original).
} 
another voice, the other is still implied, for the voice always presupposes an addressee, another voice, which itself in turn addresses another voice,' (47) Nikulin argues. Polyphony shows that dialogicality is an inextricable feature of our psychological life. For instance, when we think to ourselves or perhaps 'talk' to ourselves, we are not engaging in a monologue or soliloquy; we are engaging in a dialogue with ourselves, or we are thinking about something by including the perspectives of imagined interlocutors' voices. This means that when it comes to our psychological life, polyphony precludes monological discourse.

Notwithstanding the creative potential one has when utilizing one's expressive voice, as Nikulin argues, it remains remarkable just how much 'sameness, constancy, and coherency' (69) one characteristically has in one's voice or dialogical interaction. This consistency is what enables others in interlocutory spaces to recognize and identify one as the person one is. As Nikulin notes, this is what Bakhtin calls the person's 'nucleus' and 'personal idea' (70; Italics original). In order to distinguish this from its various historical meanings, Nikulin calls it the 'eidema' (Ibid; Italics original).

The eidema becomes the most important idea in Nikulin's philosophy of dialogue and dialogicality because, as I shall show, the eidema not only constitutes one's personal identity within dialogical communication; it is 'a condition (although not transcendental in the Kantian sense) for the possibility of being a person' (81) and a condition for the possibility of dialogue.

Nikulin emphasizes how 'It is difficult to present the eidema in terms of traditional metaphysical notions' (74; Italics original). This is because one's eidema is not a fixed entity with finite, determinate attributes capable of identification and, ultimately, of definition: '[I]t can hardly be defined in terms of "what" it is' because (1) it 'is present within an unfinalizable human interaction' and (2) 'it is not exhausted in any particular act of personal vocal expression' (Ibid). Nikulin argues that the eidema is a 'simplex,' or 'simple whole' (Ibid), which is one of the only positive identifications he makes about the eidema. Indeed, he says much more about what the eidema is not rather than what it is: e.g., 'the eidema is primarily characterized negatively...' (80; Italics original). ${ }^{9}$ For instance, he writes:

Still, in every person, the simplex of the eidema is always only partially present to the communicative and expressive act, because the fullness of one's eidema is not that of a thing; the eidema is neither a thing nor a given. Nor is the eidema a construction (social, historical, mental, psychological, circumstantial, etc.). The

\footnotetext{
${ }^{9}$ In comparing the eidema to traditional ideas in the history of Western metaphysics, he says further that the eidema is neither a constitutive nor a regulative idea, in the Kantian sense (77); it 'is neither an efficient nor a final cause that would predetermine how one acts, how one discloses oneself, or what one says in a conversation' (Ibid), as Aristotle might understand it; and, again, as has been shown above, it is not a 'Cartesian thinking substance' (78). It is not an essence, and it is not a subject or ' $I$ in any sense' either (Ibid; Italics original). Nikulin elaborates on his negative description when he says, 'Thus, the eidema is primarily characterized negatively, in what it is not; it is not a substance, not a subject, not an attribute, not a relation, not a function, not an I, not a cause, not a notion; it has no univocally defined essence, and it is distinct from anything given or preconceived within a person. Thus, not being directly accessible, the eidema cannot, properly or strictly, be logically defined, i.e., it cannot be presented as a subject that is univocally described by its attributes. As such, the eidema should be taken as not directly accessible in the fullest sense; and thus it is not accessible in thought or through any direct communication, nor is it described, intuited, revealed, etc.' (80; Italics original).
} 
eidema appears in its simplexity only when a person, as an aufgegeben or a task to be accomplished, attempts to fulfill herself communicatively with the others by expressing herself as an ever new and concrete partial realization of the unthematized fullness of her eidema (74-75; Italics original).

According to Nikulin, 'one's personal voice appears in the unity of its expressive and communicative aspects' (70). In a characteristically difficult passage, Nikulin distinguishes between the expressive and communicative aspects, and shows how the eidema serves as the mechanism which establishes such a unity. He writes,

[T] he expressive and the communicative pertain to individual otherness and sameness as they are simultaneously yet differently present through the voice. As communicative, the voice meets the other within a whole plurality of different individual and independent voices, which is a meeting that is implied in the act of utterance and communication. As expressive, the voice inevitably refers to and presents the other, doing so both to and within itself, for the voice is the person's "core." A person present qua voice thus confronts the expressive other in itself ('within') and confronts the communicative other in the other(s) ("without"), to whom one is intimately linked, yet whom one perceives as indissoluble and as the "dearest of strangers." Such an expressive other within oneself...is the "personal idea" or eidema, which is present only in communication with others.... Hence, one's eidema may be understood as the other both of and within oneself.... (7071; Italics original).

Here, the 'expressive other in itself' refers to the condition the person always finds herself in as an agent who can never exhaust (herself through), and always create anew, her expressive acts, while the 'communicative other in the other(s)' refers to the condition the person always finds herself in as an agent encountering other agents in interlocutory space. Nikulin's description suggests that one's eidema is what grounds and makes compatible one's spatio-temporal, self-same yet unfinalizable nature, while allocating room for the inexhaustibility and ever-renewability of one's expressive acts. This is because the self is never coincident with or identical to itself. Further, he says that the eidema is the 'expressive other within oneself,' so it might seem at first that the eidema is constituted much more by the expressive rather than the communicative aspects of the person's voice. But he is also quick to note that the 'expressive other' is 'present only in communication with others. ${ }^{10}$ It is clear, then, that the successful expression of one's personal voice is just as dependent on the communicative aspect as it is on the expressive aspect (i.e., one's expressive capacity and articulation). Indeed, as he argues, '[O]ne's eidema...cannot be established in the absence of the other' (72; Italics original).

Nikulin suggests that one's eidema serves as the core of one's personal identity, especially as that identity is articulated and recognized and responded to within dialogical communication with other polyphonic voices. This interpretation is corroborated by his rather bold claim that 'personal identity' should not be 'understood...

\footnotetext{
${ }^{10}$ Indeed, Nikulin writes elsewhere: 'It makes no sense to speak about an independent, preexistent eidema before an act of dialogical communication' (2006, 87 ; Italics original).
} 
biographically, socially, linguistically, etc., but rather as that which is provided by one's eidema in an effort to "spell oneself out" in one's exchanges with the others...' (71; Italics original). One's eidema, then, is one's identity as it is 'disclosed through ever renewable acts of personal communication' (Ibid).

It is unproblematic that Nikulin's description rejects the formulations that are historically associated with substance ontologies. In fact, Nikulin claims that one cannot even say that the eidema is, if one means by that it exists and is conceivable by itself (75) because it 'only exists in a constantly renewable act of human communication' (Ibid) - thus the traditional substance ontology's inability to even identify, much less understand, the role the eidema plays in human dialogical interaction. 'It is due to the presence and disclosure of the eidema as the self that one can be with others, can converse with them and can come to a realization of oneself (79; Italics original),' Nikulin writes. So, it is only because of the eidema that the self can communicate and express itself with others and yet the eidema can be actualized and manifested only through the person and with other persons in dialogical interaction. Because of the mutually reinforcing character of the relation between the eidema and the self in dialogical exchange, Nikulin maintains that the eidema in no way precedes the person either ontologically or temporally in such exchange (Ibid). ${ }^{11}$

\section{Nikulin's Account of the Relationship Between Dialogue and Agency}

Having explained the central notions — voice, polyphony, and the eidema — in Nikulin's philosophy of dialogue, I now want to turn to the first of the two main problems with Nikulin's overall account, namely, that his conception of the relationship between dialogue and agency suffers from conceptual inconsistencies.

For Nikulin, dialogue is not undertaken for the interlocutors to reach consensus. ${ }^{12}$ In fact, Nikulin denies, like Gadamer, that dialogue has any telos at all. Nikulin claims that 'consensus is impoverished; it is a sui generis condition for the impossibility of dialogue. Consensus cancels the very possibility of any continuation of the unfinalizable dialogical exchange' (221; Italics original). (He reiterates this claim in Dialectic and Dialogue. $)^{13}$ Nikulin clearly favors the continuation of dialogue for dialogue's sake over dialogue's eventual culmination in consensus. Dialogue is its own reward, on his view, insofar as it offers the possibility for human beings to present

\footnotetext{
${ }^{11}$ Rather remarkably, Nikulin drops all mention of the term eidema from the later Dialectic and Dialogue, and yet retains both the notion of the 'personal other' and the components constitutive of the eidema, although in Dialectic and Dialogue he couches them in a different context, namely, in a discussion of what makes a conversation a dialogue.

${ }^{12} \mathrm{He}$ says, for instance, 'The reason for this is that dialogue does not have an end in consensus; rather, it essentially presupposes dissensus of a certain kind... whereby every interlocutor retains his position and attempts to clarify (and possibly modify) it for himself, and, at the same time, for the other, thus also clarifying the other's position for himself and for the other' (142; Italics original).

${ }^{13}$ In Dialectic and Dialogue, Nikulin says, 'A certain kind of disagreement constitutes the life of dialogue, whereas complete agreement means the death of dialogue and thus also the end of being, if to be is to be in dialogue. In dialogue, relations with the other are not smooth; dialogue implies a disagreement that nevertheless allows for interaction and reciprocal recognition of the other, including one's personal other. This reciprocity between interlocutors allows them to mutually support each other in an ongoing dialogical effort to realize and reciprocally understand the other person and the other of oneself' $(2010,81)$.
} 
or express themselves in all of their humanity, yet never finally or exhaustively. Nikulin addresses this when he writes,

[D]ialogue's main intention is not that of winning an argument for the sake of establishing oneself or one's own ego-as if one's subjectivity were only achieved once it has been imposed upon the other-but rather it is to provide the chance for opening up a conversational clearing whereby that which every interlocutor already has may appear even though he did not yet have the chance to present it, either to himself or to others, or thus to realize it (142).

Nikulin's view that dialogue lacks a telos is underscored by his additional claim that interlocutors in dialogue lack autonomy.

Now, what is autonomy for a person who is involved in dialogical interaction with others? Since in dialogue every person unfinalizably, i.e., meaningfully yet desperately, tries to put forth and express her personal other, there can hardly be a proper autonomy of the person insofar as she always tries to elucidate that which is not herself as, in fact, her I, i.e., that which does not belong to her subjectivity (see Chapter 4) and which she thus cannot handle according to her will or desire, and which she cannot change in any way (228; Italics mine).

Thus, even if there were, hypothetically, a telos to dialogue, the interlocutors, lacking autonomy in the dialogical encounter, would not have the means by which to actualize that telos. Nikulin claims that interlocutors in dialogue lack autonomy because of the role the eidema plays, that is, that one's effort to express oneself will always involve trying to express that part which is 'other both of and within oneself' (70-71). And he elaborates on this claim (that interlocutors lack autonomy) by offering an account of 'allonomy,' which I shall discuss later.

For now, I want to suggest that, while Nikulin's conception of the eidema is no doubt insightful, he nevertheless ascribes too much power to it and too little agentive power to the interlocutors themselves. He makes a rather bold claim, for example, regarding the interlocutors' agency when, in describing his contention with Taylor's view, he says: 'Furthermore, dialogue must imply a mutual and potentially reciprocal inter-action, as precisely an inter-action, between the speakers and "locutors," who thus become "interlocutors." However, such interaction is not a sharing of agency, or even a mode of it, contra Charles Taylor's contention' (143; Italics mine).

What could Nikulin mean by saying that the 'mutual and potentially reciprocal interaction' is not 'even a mode of' agency? What then does he mean by 'agency'? Dialogue, at its most basic level, must presuppose some degree of human agency. His claims on this point seem tantamount to the view that interlocutors do not have any control over their actions in dialogue. But this possibility seems to conflict with his claims elsewhere such as the following: 'a person must be wholly involved in dialogue, with all of her (dialogical) being, mit dem ganzen Wesen, to use Buber's phrase' (157; Italics original), and 'Dialogue is an exchange of rejoinders between the multiple and independent voices of real others, of persons who are striving toward the expression or the revealing of their eidemata qua personal other...' (154-155; First italics mine), and lastly 
To be in dialogue is, first and foremost, to communicate with the other; it is to be with the other and to attend to the other, and it is to return back to oneself only through the other without ever having left oneself; it is to return to the unfinalizable yet definite realization of oneself in and from one's personal other (242; Italics mine).

Three questions arise here. First, what does it mean for a person to be 'wholly involved in dialogue' if that excludes agentive activity? Second, how is 'striving toward the expression or the revealing of...eidemata' non-agentive? And third, how are 'communicat[ing] with,' 'being with,' and 'attend[ing] to' the other non-agentive? I am not sure what possible answer Nikulin can give to these questions.

His claims seem to conflict as well with the fact that he distinguishes between truly dialogical interactions - i.e., dialogues - and what he calls 'non-dialogical conversation[s] (156),' a distinction he maintains in Dialectic and Dialogue. ${ }^{14} \mathrm{~A}$ 'non-dialogical conversation' is '[a]n exchange of rejoinders that simply conveys information' (Ibid; Italics mine). Because he says elsewhere that '[d]ialogue [too] is an exchange of rejoinders...' (154), it seems that the relevant difference here is that 'non-dialogical conversation[s]' are simply 'information-conveying.' In order to distinguish between these different types of encounters, he must ascribe some degree of volition to the interlocutors involved, because surely part of what makes a 'non-dialogical conversation' fail to be a dialogue is the action of the interlocutors, e.g., failing to present themselves in a sufficiently revelatory way. ${ }^{15}$ For instance, he identifies, rightly, that benevolence is paramount for an interlocutory encounter to be dialogical.

I cite him at length here because, in emphasizing the importance of benevolence on the part of the interlocutors, the passage offers strong evidence for why dialogue has to be a 'mode' of agency, even though Nikulin claims otherwise:

Dialogical partners need to exercise their goodwill in order to make dialogue possible, i.e., to be capable of being and remaining in dialogue, for otherwise, if a person is determined to reject the other, e.g., in an effort to establish one's alleged superiority or honor, then dialogue becomes impossible. Benevolence as goodwill can be taken, then, as the readiness to listen to the other, to be mutually with the other and recognize him in reciprocity even when allosensually disagreeing with him, and thus not to neglect oneself.

Benevolence in dialogue is implied in mutuality and even more so in reciprocity. Indeed, the other cannot be present as an interlocutor unless one does not already implicitly accept him in his as of yet not spelled-out being in dialogue. One already is with the other in mutuality, and benevolence is a kind of presentiment of the dialogical involvement, an acceptance of the other even if the other is not yet recognized in reciprocity. Benevolence can be taken, then, as a sui generis

\footnotetext{
${ }^{14}$ See especially Nikulin 2010, 74 where he talks about the 'four components [that] turn conversation into dialogue.' For example, he says there that 'It is my claim here that the following four components turn conversation into dialogue: personal other, voice, unfinalizability, and allosensus...' (Ibid).

${ }^{15}$ Indeed, Nikulin insists on the revelation or disclosure of being that occurs in dialogue: '[D]ialogue allows for the person to realize and disclose herself in her eidema within dialogue but not to construct herself, i.e., not to produce herself for the first time' (2006, 232; Italics original).
} 
precondition of and for dialogue in mutual relation with the other, which, once recognized, becomes reciprocal (252; Italics original).

In this passage, Nikulin's talk of 'dialogical partners...exercis[ing] their goodwill' and their 'readiness to listen to the other' strongly suggests that he is relying, however tacitly, on a conception of dialogue as a mode of agency, even though he explicitly claims otherwise.

Nikulin explicitly denies that dialogue is a mode of agency because he insists that interlocutors in dialogue inevitably find themselves swept up and carried along by the relational dynamics of the event of dialogue. Because the person in dialogue is neither wholly dependent on nor wholly independent of the other(s), he claims that 'neither the notion of autonomy nor that of heteronomy properly characterizes a person's relation(s) to herself and to the others in dialogue' (228).

Central to Nikulin's position regarding dialogue and agency is his view that dialogue is 'allosensual.' By allosensual, Nikulin means that the person in dialogue needs and depends on the other yet is simultaneously independent of the other as someone who may disagree with them (Ibid). Because dialogue is allosensual, he claims that 'allonomy,' rather than autonomy and heteronomy, accurately 'characterizes the dialogical situation' (Ibid). For Nikulin, 'A person is to be taken as allonomous in dialogue insofar as she is defined both by the other who is another to herself (the other person) and by the other who is not another to herself (the personal other)' (Ibid).

This notion of allonomy helps show why, as I suggested earlier, in the context of a consideration of dialogical agency, Nikulin ascribes too much power to the eidema. I agree with Nikulin that dialogue should not be characterized solely by the notion of autonomy, understood primarily as 'rational will' (227). There is undeniably a significant part of the dialogical encounter that remains out of the interlocutors' control while they are in it, not the least of which are the others' words and actions. And, indeed, as Nikulin's conception of benevolence suggests, the more one interlocutor tries to impose her will to control on the encounter, the worse the encounter will likely unfold. But Nikulin's position regarding the eidema leads him to underestimate the role that agency plays in dialogue. That the eidema involves one's efforts to express that part of oneself which is 'other both of and within oneself' (70-71) - and that the notion of the eidema plays such a fundamental role in his philosophy of dialog-leads Nikulin to conclude that there is more outside of each interlocutor's control than there actually is. This is also, I suspect, why he thinks consensus occurs only accidentally, if at all.

Nikulin even suggests that 'the agreement to be in dialogue cannot be chosen' (223).

[T] he agreement to be in dialogue cannot be chosen, first, insofar as it is allosensual and thus excludes the chance of ever arriving at a finalizing agreement, and second, because being (as dialogical being) is and thus cannot be chosen; for to choose something is to notice and to thematize it as that which is desired, whereas once one is (allosensually and unfinalizably) in dialogue, one is already in it, such that any realization, reflection, or understanding of it always occurs (too) late (Ibid; Italics original).

This description is consistent with his view that dialogue is not a mode of agency, but it seems more a philosopher's creative fiction than a phenomenologically accurate 
depiction of lived experience. Unpacking the above passage, his argument is as follows: both 'finalizing agreement' and 'thematiz[ation]' are necessary conditions for a dialogue's being able to be chosen, and since these conditions are absent in all dialogue, then dialogue can never be chosen. (While it is unclear precisely what he means by thematizing something, presumably he means that to thematize something is to make it explicit to oneself.) But nothing prevents one's agreement to be in dialogue from being provisional and tacit, and not finalizing and explicit, and yet still being chosen as such. Indeed, the provisional and tacit characterize how dialogue is often undertaken in real life.

\section{Nikulin on the Necessary and Sufficient Conditions for Dialogue}

The second significant problem with Nikulin's account is the way he conceptualizes the necessary and sufficient conditions for dialogue. He writes,

Are there necessary and sufficient conditions for dialogue? To be sure, there should be a plurality of interlocutors. Yet beyond this there seem to be no necessary or sufficient conditions for dialogue: it can originate in the most unexpected of situations and circumstances. The event of being in dialogue is not conditioned; it is a wonder (258; Italics original).

There are three issues here that require address. The first issue is as follows. Nikulin claims that 'a plurality of interlocutors' is the sole necessary and sufficient condition for an interlocutory encounter to be dialogue. He also insists on distinguishing between dialogue and 'non-dialogical conversations.' But if 'non-dialogical conversations' have a 'plurality of interlocutors,' that is, if they have met the sole necessary and sufficient condition for being dialogue, then how do they not count as instances of dialogue? Nikulin's answer, presumably, would be that dialogue involves more than a mere 'exchange of rejoinders that simply conveys information' (156), as 'non-dialogical conversations' do. But if this is the case, then he needs to account for it by identifying more than the one necessary condition of a 'plurality of interlocutors' of dialogue.

The second issue is more straightforward. Again, Nikulin's claim is that 'a plurality of interlocutors' is a necessary and sufficient condition for dialogue. But, as I noted above, he makes the following claim as well: 'Dialogical partners need to exercise their goodwill in order to make dialogue possible, i.e., to be capable of being and remaining in dialogue, for otherwise, if a person is determined to reject the other, e.g., in an effort to establish one's alleged superiority or honor, then dialogue becomes impossible' (252; Italics mine). This passage indicates that 'goodwill,' or what he elsewhere refers to as 'benevolence,' is a necessary condition for dialogue, which poses a contradiction to his claim that 'a plurality of interlocutors' is a necessary and sufficient condition for dialogue.

And the third issue is that Nikulin strongly suggests that assuming relations of equality among the interlocutors is a necessary condition for dialogue.

Dialogue not only allows for equality but is furthermore not even possible without presupposing the equality of the interlocutors. Every participant in a 
dialogue is equal to the other participants, i.e., not through a leveling within the social but as a person who has a voice and who is capable of being engaged with the other in an expression of her personal eidema (170; Italics original).

Again, this contradicts his claim that 'a plurality of interlocutors' is a necessary and sufficient condition for dialogue. I should note that here I have identified this claimthat dialogue presupposes the equality of the interlocutors - only to show that it contradicts his claim that 'a plurality of interlocutors' is a necessary and sufficient condition for dialogue. But, of course, I should ask whether his claim about interlocutory equality is even true. It is clear that he remains steadfast in his view on this: as he says in Dialectic and Dialogue, 'From what has been said about the personal other, it is evident that dialogue implies equality among interlocutors and their voices. Everyone is equal with everyone in dialogue qua dialogical partner. Therefore, a proper dialogical discussion suspends and cancels social and other inequalities' (2010, 81; Italics original).

By arguing that 'dialogical discussion suspends and cancels social and other inequalities,' Nikulin seems to have in mind something similar to Robert Solomon's account of how the private dimension of romantic love suspends the public dimension that otherwise affects the people involved. As Solomon (2006) says,

The equality that is demanded by love begins with this refusal to be measured by any 'external' standards. Social power, wealth, public acclaim or popularity, physical strength and attractiveness are all rendered irrelevant to the mutual evaluation that takes place in love. They all disappear in favor of the very different concerns of intimacy and private virtue $(2006,290)$.

So Nikulin may be saying that, similar to Solomon's account of the private dimension of romantic intimacy, true dialogue requires that the interlocutors see each other as equals, even if this likely involves one of them consciously suspending the social authority they may ordinarily have in public life. It would likely be more difficult, I think, for interlocutors to suspend the power dynamics of the public dimension than it would be for romantic partners, if for no other reason than that the interlocutors' activity takes place and remains in the public dimension, whereas the romantic partners' intimacy often occurs in the private dimension and is thus shielded to some extent from the pervasive power dynamics of the public dimension. Nevertheless, I think it is certainly possible for interlocutors to allow themselves to be stripped of socially unequal roles in much the same way that 'two people in bed are stripped of all public roles and power' (291), but it would require a strong, conscientious effort on their part.

As I have shown in this section, while Nikulin claims explicitly that there is only one necessary and sufficient condition for dialogue - i.e., a 'plurality of interlocutors' (2006, 258) - his overall account shows that there are five necessary conditions, which, when collectively fulfilled, would be sufficient for dialogue: (1) a plurality of interlocutors, (2) some degree of revelation (of the interlocutors' eidemata), that is, something more than the mere conveyance of information, (3) benevolence, (4) equality, and of course (5) the fundamental condition for dialogue - the eidema. 


\section{Conclusion}

A potential objection ${ }^{16}$ to the critical account I have offered above of Nikulin's conception of the relationship between dialogue and agency is that Nikulin is primarily concerned with the ontological aspect of dialogue and that, for him, since to be is just to be in dialogue, agency is nothing more than being in dialogue. So, the objection would go, my criticism of his views regarding dialogue and agency is unfair. Indeed, there is significant support for the claim that he is focused primarily on the ontology of dialogue, e.g., his view that dialogue is not simply an aspect of the human condition but rather that it is the human condition (34), and his explicit claim that a 'plurality of interlocutors' (258) is the sole necessary and sufficient condition for dialogue.

However, there are two even stronger reasons which support my critical reading of Nikulin's account of the relationship between dialogue and agency. That Nikulin's account (1) includes (albeit tacitly) multiple necessary conditions for dialogue, including ones such as benevolence, which are clearly agent-dependent, and (2) identifies dialogues and 'non-dialogical conversations' as distinct phenomena, shows that the normative dimension of dialogue occupies a significant place in his account. These two features of Nikulin's account demonstrate that he does recognize-again, albeit tacitly - that dialogical agency has to be more robust than his focus on its ontology would suggest.

Notwithstanding the problems with Nikulin's account that I have identified, he offers many insights into dialogue and the dialogical self, and there is much in On Dialogue and Dialectic and Dialogue that pushes forward the philosophical conversation on these subjects. Indeed, one can benefit from taking seriously many of his most provocative claims, like when he says in Dialectic and Dialogue, 'dialogue is the most engaging and dignified activity proper to humans' $(2010,82)$. I have set out to identify and discuss the two main problems with Nikulin's account because getting a better understanding of such an important account will enrich contemporary philosophical discussions of dialogue and the dialogical self.

Acknowledgements I want to thank the anonymous reviewers for their insightful comments on an earlier draft of this paper. I also want to thank Michael Butler and Anthony Vincent Fernandez for their helpful remarks on an earlier draft of this paper. Any failings in what follows are my responsibility alone.

\section{References}

Bakhtin, Mikhail. 1982a. The dialogic imagination: four essays by M.M. Bakhtin. Ed. by M. Holquist. Austin: University of Texas Press.

Bakhtin, Mikhail. 1982b. "Discourse in the novel." The dialogic imagination: four essays by M.M. Bakhtin. Ed. by M. Holquist. Austin: University of Texas Press.

Bakhtin, M. (1984a). Problems of Dostoevsky's poetics. Minneapolis: University of Minnesota Press.

Bakhtin, M. (1984b). "Toward a reworking of the Dostoevsky book.” Appendix 2 in Problems of Dostoevsky's poetics. Ed. and trans. by Caryl Emerson. pp. 283-302. Minneapolis: University of Minnesota Press.

Bakhtin, Mikhail. 1986. Speech genres and other late essays Ed. by Caryl Emerson and Michael Holquist. Trans. By Vern W. McGee. Austin: Univ. of Texas press.

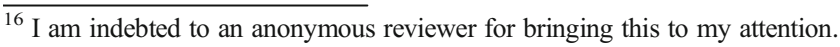


Butler, Edward P. 2007. On Dialogue review essay. Pp. 167-176. In Graduate Faculty Philosophy Journal. Vol. 28, No. 2. New York: The New School for Social Research.

Cole, E. B. (1993). “Body, mind, and gender.” From chapter three of philosophy and feminist criticism: An Introduction. Middletown: Paragon Press.

Fritz, J. H. (2015). Plato and the elements of dialogue. Lanham: Lexington Books.

Gadamer, H.-G. (2004). Truth and method (2nd ed.). New York: Bloomsbury Academic.

Heidegger, M. (2008). Being and time. Trans. by John Macquarrie and Edward Robinson, with new foreword by Taylor Carman. New York: Harper and Row Publishers, Inc.

Held, V. (1990). Feminist transformations of moral theory. Philosophy and Phenomenological Research, 50, 321-344 Autumn. International Phenomenological Society.

Hermans, H. J. M. (2001). The dialogical self: toward a theory of personal and cultural positioning. Culture \& Psychology, 7(3), 243-281 September.

Hermans, H. J. M. (Ed.). (2012a). Applications of dialogical self theory: new directions for child and adolescent development. San Francisco: Jossey-Bass.

Hermans, Hubert J.M. 2012b. Between dreaming and recognition seeking: the emergence of dialogical self theory. Lanham: University Press of America, Inc.

Hermans, H. J. M., \& Dimaggio, G. (2016). The dialogical self in psychotherapy: an introduction. New York: Routledge.

Hermans, H. J. M., \& Gieser, T. (Eds.). (2014). Handbook of Dialogical Self Theory. Cambridge: Cambridge University Press.

Hermans, H. J. M., \& Hermans-Konopka, A. (2010). Dialogical self theory: positioning and counterpositioning in a globalizing society. Cambridge: Cambridge University Press.

Hermans, H. J. M., \& Kempen, H. J. G. (1993). The dialogical self: meaning as movement. San Diego: Academic Press, Inc..

Hermans, Hubert J.M., Harry J.G. Kempen, and Rens J.P. van Loon. 1992. "The dialogical self: beyond individualism and rationalism." Pp. 23-33. In American Psychologist. 47. January.

Kögler, Hans-Herbert. 2010. "Being as dialogue, or the ethical consequences of interpretation." Consequences of hermeneutics: fifty years after Gadamer's Truth and method. Ed. by Jeff Malpas and Santiago Zabala. Evanston: Northwestern University Press.

Lysaker, P., \& Lysaker, J. (2008). Schizophrenia and the fate of the self. New York: Oxford University Press.

Miller, Mitchell. 2011. Dialectic and Dialogue review essay. Pp. 177-189. In Graduate Faculty Philosophy Journal. Vol. 32, No. 1. New York: The New School for Social Research.

Nikulin, D. (2006). On Dialogue. Lanham: Lexington Books.

Nikulin, D. (2010). Dialectic and dialogue. Stanford: Stanford University Press.

Rule, P. N. (2015). Dialogue and boundary learning. Rotterdam: Sense Publishers.

Russell, L. D. (2012). Creating meaning from chaos: narrative and dialogic encounters in family crisis. Qualitative Inquiry, 18(5), 391-400.

Solomon, R. (2006). About love: reinventing romance for our times. Indianapolis: Hackett Publishing Company, Inc..

Taylor, C. (1985a). Philosophical papers, volume I: human agency and language. Cambridge: Cambridge University Press.

Taylor, C. (1985b). Philosophical papers, volume II: philosophy and the human sciences. Cambridge: Cambridge University Press.

Taylor, Charles. 1992a. "The dialogical self." The interpretive turn: philosophy, science, culture. Ed. by David R. Hiley, James F. Bohman, and Richard Shusterman. Ithaca: Cornell University Press.

Taylor, C. (1992b). Sources of the self: the making of the modern identity. Cambridge: Harvard University Press.

Trimble, L. (2009). Transformative conversations about sexualities pedagogy and the experience of sexual knowing. Sex Education, 9(1), 51-64.

Publisher's Note Springer Nature remains neutral with regard to jurisdictional claims in published maps and institutional affiliations. 